\title{
High blood levels of soluble OX40 (CD134), an immune costimulatory molecule, indicate reduced survival in patients with advanced colorectal cancer
}

\author{
RYOICHI SAWADA ${ }^{1}$, YOSHINORI ARAI ${ }^{1}$, YUKIKO SAGAWA ${ }^{2}$, YUSUKE NAGATA ${ }^{1}$, TAKASHI NISHIMURA ${ }^{1}$, \\ MASAAKI NOGUCHI $^{1}$, KATSUSHI AMANO ${ }^{1}$, SEIJI ARIHIRO ${ }^{1}$, MASAYUKI SARUTA ${ }^{1}$ and SADAMU HOMMA ${ }^{2}$ \\ ${ }^{1}$ Division of Gastroenterology and Hepatology, Department of Internal Medicine, ${ }^{2}$ Division of Oncology, \\ Research Center for Medical Sciences, The Jikei University School of Medicine, Tokyo 105-8461, Japan
}

Received March 13, 2019; Accepted July 12, 2019

DOI: 10.3892/or.2019.7304

\begin{abstract}
The interaction between tumor necrosis factor receptor superfamily, member $4(\mathrm{OX} 40)$ on $\mathrm{T}$ cells and the OX40 ligand (OX40L) on antigen-presenting cells (APCs) is a pivotal step for T-cell activation and the promotion of antitumor immunity. However, it is hypothesized that soluble OX40 (sOX40) in blood suppresses T-cell activation by blocking the OX40/OX40L interaction. In the present study, the association between blood sOX40 levels and the clinical characteristics of advanced colorectal cancer (CRC) patients was investigated. Blood was collected from 22 patients with advanced CRC. Blood sOX40 levels were determined by enzyme-linked immunosorbent assay (ELISA). Messenger RNA (mRNA) expression encoding OX40 or cytokines was analyzed by quantitative RT-PCR. Blood sOX40 levels were positively correlated with the blood levels of carbohydrate antigen (CA) 19-9, carcinoembryonic antigen (CEA), $\mathrm{C}$-reactive protein (CRP) and soluble programmed cell death ligand-1 (PD-L1) in patients but negatively correlated with the blood levels of albumin. Blood sOX40 levels were not correlated with the mRNA expression of interferon (IFN)-gamma, interleukin (IL)-6, IL-10 and IL-4 in the peripheral blood
\end{abstract}

Correspondence to: Professor Sadamu Homma, Division of Oncology, Research Center for Medical Sciences, The Jikei University School of Medicine, 3-25-8 Nishi-shimbashi, Minato-ku, Tokyo 105-8461, Japan

E-mail: sahya@jikei.ac.jp

Abbreviations: APC, antigen-presenting cell; CEA, carcinoembryonic antigen; CRP, C-reactive protein; CRC, colorectal cancer; ELISA, enzyme-linked immunosorbent assay; IFN, interferon; IL, interleukin; OX40L, OX40 ligand; PBMC, peripheral blood mononuclear cell; PD-1, programmed cell death-1; PD-L1, programmed cell death-ligand 1; PMA, phorbol 12-myristate 13-acetate

Key words: OX40, soluble OX40, colorectal cancer, biomarker, survival, T-cell activation, antitumor immunity mononuclear cells (PBMCs) of the patients and were not correlated with the frequency of programmed cell death-1 (PD-1) expressing $\mathrm{CD}^{+}, \mathrm{CD}^{+}$and $\mathrm{CD}^{+} 6^{+}$cells. Notably, according to both univariate and multivariate analyses, high blood sOX40 levels were significantly correlated with a reduced survival time in patients. Although activated Jurkat cells (a human $\mathrm{T}$ cell line) exhibited an upregulation of sOX40 production and OX40 mRNA expression, the OX40 mRNA expression of the PBMCs of patients was not correlated with blood sOX40 levels. High blood levels of sOX40 were correlated with a reduced survival time in patients with advanced CRC, possibly associated with the suppression of antitumor immunity by sOX40.

\section{Introduction}

The immune status in the tumor microenvironment appears to be an important factor in determining the progression of cancer (1). Tumor-infiltrating lymphocytes (TILs), effectors of cell-mediated antitumor immunity, are closely associated with tumor growth, metastasis and chemoresistance in colorectal cancer (CRC), affecting the prognosis of CRC. It has been reported that a dense infiltration of TILs is correlated with an improved survival outcome in CRC (2-4). A high density of TILs in the metastatic tumor is also correlated with better relapse-free and overall survival rates after resection of the metastatic tumor $(5,6)$. Abundant TIL infiltration is correlated with improved efficacy of neoadjuvant chemoradiotherapy in patients with locally advanced rectal cancer (7) and in those with a distant metastatic tumor (8). The measurement of TILs in the primary tumor using the method proposed by the International TILs Working Group (https://www.tilsinbreastcancer.org) can be used as a prognostic marker for the clinical effectiveness of palliative chemotherapy in patients with stage IV CRC (9).

Antitumor immune activity is accelerated or suppressed by the delicate balance between immune-stimulating and immune-suppressive networks. T cell-mediated antitumor immunity is regulated by the interaction between receptors and ligands of costimulatory or coinhibitory immune checkpoint molecules (10). PD-1 is one of the pivotal 
coinhibitory molecules, and the blockade of the interaction between PD-1 and its ligand, programmed cell death ligand-1 (PD-L1), by monoclonal antibodies leads to the activation of T cell-mediated antitumor immunity and successful anticancer treatment $(11,12)$.

Tumor necrosis factor receptor superfamily, member 4 (TNFRSF4) is also known as OX40 (CD 134) (13). It is a costimulatory immune checkpoint molecule, and its expression is induced on $\mathrm{T}$ cells by activation (14). OX40 ligand (OX40L) is expressed on activated APCs (15). The binding of OX40L to OX40 on T-cells generates an efficient clonal expansion and the effective primary responses of $\mathrm{CD}^{+}$and $\mathrm{CD}^{+}$ T cells $(14,16,17)$. It is also known that the OX40/OX40L interaction blocks natural regulatory T-cell activity and inhibits inducible regulatory T-cell generation $(18,19)$. It has been reported that an artificially enhanced OX40/OX40L interaction could induce antitumor effector $\mathrm{CD}^{+}$and $\mathrm{CD}^{+} \mathrm{T}$ cells and suppress Treg activity, resulting in an increase of effective antitumor immunity (20-22).

Recently, it was reported that the soluble form of OX40 (sOX40) exists in human blood and could be quantitatively detected by enzyme-linked immunosorbent assay (ELISA) (23). If sOX40 has a binding site to OX40L, it has the capacity to bind to OX40L on APCs, leading to the blockade of the natural OX40/OX40L interaction, resulting in a suppression of T-cell activation. In fact, an administration of soluble OX40-Ig fusion protein, which can bind to OX40L and inhibit the OX40/OX40L interaction, suppressed the immune activity that generates experimental autoimmune encephalomyelitis in an animal model (24). In the present study, it was revealed that $\mathrm{sOX} 40$ is detectable in the blood of patients with $\mathrm{CRC}$, indicating that high blood levels of sOX40 may affect antitumor immunity against CRC. In the present study, the association of blood sOX40 levels and clinical characteristics of CRC was investigated.

\section{Materials and methods}

Patients. Blood samples and clinical information were retrospectively collected from 22 patients who had been histologically or cytologically diagnosed with advanced CRC or postsurgical recurrent CRC at The Jikei University Hospital (Tokyo, Japan). Survival was defined as the period from blood sample collection to death or the last follow-up observation. The study protocol was approved by the Ethics Committee of The Jikei University School of Medicine (30-397 9418) and conducted in accordance with the Declaration of Helsinki.

Sample collection, procedure and restoration. Blood was collected into a cell preparation tube with sodium citrate (BD Vacutainer ${ }^{\circledR} \mathrm{CPT}^{\mathrm{TM}}$; BD Biosciences) and centrifuged at $620 \mathrm{x} \mathrm{g}$ at room temperature for $20 \mathrm{~min}$. Plasma samples were stored in $1-\mathrm{ml}$ aliquots at $-80^{\circ} \mathrm{C}$. Peripheral mononuclear cells (PBMCs) were collected and frozen-stored using Cell Reservoir One (Nacalai Tesque, Inc.).

Quantification of sOX40. Blood sOX40 concentrations were measured using an ELISA kit for sOX40 (Immuno-Biological Laboratories, Ltd.) according to the manufacturer's protocol. The quantitative range was 15.6-1,000 pg/ml. Blood levels of
Table I. Characteristics of the CRC patients.

\begin{tabular}{lcc}
\hline Patients characteristics & No. of patients & $(\%)$ \\
\hline Sex & & \\
Male & 12 & 54.5 \\
Female & 10 & 45.5 \\
Age (years) & & \\
Median & 71.5 & \\
Range & $29-81$ & \\
Status & & \\
Firstly diagnosed & 9 & 59.9 \\
Postsurgical recurrence & 13 & \\
Primary site & & 45.5 \\
Ascending colon & 10 & 0 \\
Transverse colon & 0 & 4.5 \\
Descending colon & 1 & 18.2 \\
Sigmoid colon & 4 & 31.8 \\
Rectum & 7 &
\end{tabular}

Metastatic site

Liver 11

Lung $\quad 7$

Peritoneum 7

Lymph nodes 4

Histologic subtype

tub1

tub2

Unknown

$\begin{array}{ll}8 & 36.4 \\ 4 & 18.2\end{array}$

$10 \quad 45.5$

RAS mutation

Wild type 5

22.7

Mutation type

36.4

Unknown

40.9

Stage

II

9.1

III

9.1

IV

81.8

ECOG PS

0

86.4

1

13.4

Chemotherapy line

$\begin{array}{lrr}\text { Adjuvant } & 4 & 18.2\end{array}$

$\begin{array}{lll}1 \mathrm{st} & 18 & 81.8\end{array}$

History of Chemotherapy

Yes

3

13.6

No

19

86.4

CRC, colorectal cancer; tub, tubular adenocarcinoma; ECOG PS, Eastern Cooperative Oncology Group Performance Status.

sOX40 in normal healthy subjects were $78.7 \pm 28.5 \mathrm{pg} / \mathrm{ml}$. Each sample was analyzed in duplicate. The quantity of sOX40 in the culture supernatants of Jurkat cells was determined using the same ELISA assay kit. 
Table II. Correlation between blood sOX40 levels and characteristics of CRC patients.

\begin{tabular}{lcc}
\hline Variables & $r$ & P-value \\
\hline Age (years) & 0.130 & n.s. \\
Sex: Male/female & -0.264 & n.s. \\
Survival time (days) & -0.710 & $<0.001$ \\
Laboratory findings & & \\
CA19-9 (U/ml) & 0.665 & $<0.001$ \\
CEA (ng/ml) & 0.541 & 0.009 \\
CRP (mg/dl) & 0.807 & $<0.001$ \\
LDH (U/l) & 0.275 & n.s. \\
Albumin $(\mathrm{g} / \mathrm{dl})$ & -0.594 & 0.004 \\
WBC (cells/ $\mu \mathrm{l})$ & 0.170 & $\mathrm{n} . \mathrm{s}$. \\
Lymphocyte $($ cells/ $\mu \mathrm{l})$ & -0.270 & $\mathrm{n} . \mathrm{s}$. \\
Lymphocyte $(\%)$ & -0.319 & $\mathrm{n} . \mathrm{s}$. \\
Monocyte $(\mathrm{cells} / \mu \mathrm{l})$ & 0.111 & $\mathrm{n} . \mathrm{s}$. \\
Monocyte $(\%)$ & -0.032 & $\mathrm{n} . \mathrm{s}$. \\
sPD-L1 & 0.566 & 0.006 \\
\hline
\end{tabular}

Correlation was analyzed by Pearson's correlation coefficient. $\mathrm{P}<0.05$ indicated a significant difference in correlation between the two indexes. There was a positive correlation between the serum level of OX40 and that of CA19-9, CEA, CRP and sPD-L1. There was a negative correlation between the serum level of OX40 and that of albumin. There was a negative correlation between the serum level of OX40 and survival time. sOX40, soluble OX40; CRC, colorectal cancer; $r$, Pearson's correlation coefficient; n.s., not significant; CA19-9, carbohydrate antigen 19-9; CEA, carcinoembryonic antigen; CRP, C-reactive protein; LDH, lactate dehydrogenase; WBC, white blood cell.

Cell culture. Jurkat cells (25), a human T cell line, were obtained from the American Type Culture Collection (ATCC) and cultured in RPMI-1640 medium supplemented with $10 \%$ fetal bovine serum, 100 units $/ \mathrm{ml}$ penicillin and $100 \mu \mathrm{g} / \mathrm{ml}$ streptomycin. Phorbol 12-myristate 13-acetate (PMA; Sigma-Aldrich; Merck KGaA) was used for the activation of Jurkat cells.

Flow cytometry. Cell surface OX40 expression was examined by flow cytometry. A suspension of untreated or PMA-treated Jurkat cells was stained with phycoerythrin (PE)-conjugated anti-human OX40 (clone Ber-ACT35; BioLegend, Inc.) and the appropriate isotype controls (BioLegend, Inc.) for $30 \mathrm{~min}$ at $4^{\circ} \mathrm{C}$ in the dark. Cells were analyzed on a MACSQuant Analyzer (Miltenyi Biotec $\mathrm{GmbH}$ ) using MACSQuantify Software Version 2.0.

Quantitative RT-PCR. Quantitative RT-PCR was performed as previously described (26). TaqMan primers for the IL-6 (Assay ID: Hs00174131_m1), IL-10 (Assay ID: Hs00961622_ m1), IL-4 (Assay ID: Hs 00174122_m1), IFN- $\gamma$ (Assay ID: Hs00989291_m1), OX40 (Assay ID: Hs00937195_g1) and 18S ribosomal RNA (Assay ID: Hs99999901_s1) genes were purchased from Applied Biosystems. Relative expression was calculated using the $\Delta \Delta \mathrm{Cq}$ method (27).
Table III. Correlation between blood sOX40 levels and the immunological markers of the CRC patients.

\begin{tabular}{lcc}
\hline Variables & $r$ & P-value \\
\hline Interleukin-6 & -0.056 & n.s. \\
Interleukin-10 & 0.094 & n.s. \\
Interleukin-4 & 0.155 & n.s. \\
Interferon- $\gamma$ & -0.181 & n.s. \\
IL-10/IFN- $\gamma$ & 0.244 & n.s. \\
PD- $1^{+}$CD4 ${ }^{+}$ & -0.269 & n.s. \\
PD- $1^{+}$CD ${ }^{+}$ & -0.227 & n.s. \\
PD- $1^{+}$CD56 & -0.237 & n.s. \\
\hline
\end{tabular}

sOX40, soluble OX40; CRC, colorectal cancer; $r$, Pearson's correlation coefficient; n.s., not significant; IL, interleukin; IF, interferon; PD-1, programmed cell death 1.

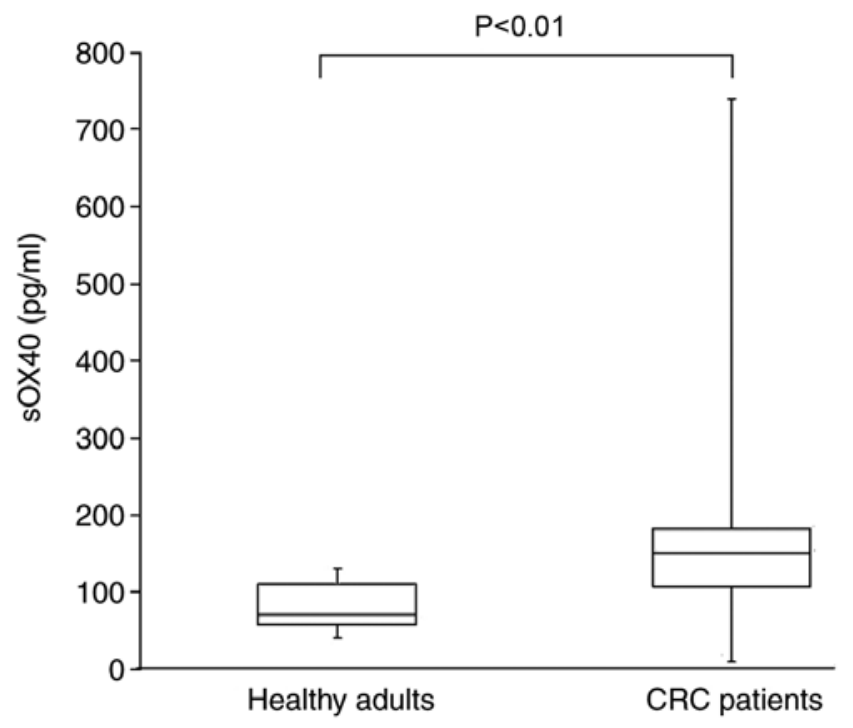

Figure 1. Distribution of blood sOX40 levels of healthy adults and CRC patients. The statistical difference was determined by Mann-Whitney U test. CRC, colorectal cancer; sOX40, soluble OX40.

Statistical analysis. The software package StatFlex (version 6; Artech Co., Ltd., Osaka, Japan) was used for statistical analysis. Pearson's correlation coefficient was used to analyze the association of OX40 levels with clinical characteristics. Univariate and multivariate Cox proportional hazards models were performed to obtain prognostic factors. Survival analysis was performed using the Kaplan-Meier estimate. P-values were calculated according to the log-rank test. $\mathrm{P}<0.05$ was considered as statistically significant.

Data of ELISA and flow cytometry in the experiments using Jurkut cells are presented as the mean \pm standard deviation (SD). Comparisons between the untreated control and drug-treated groups were performed by Dunnett's multiple comparisons test. The software package GraphPad Prism 7 version (GraphPad Software, Inc.) was used for statistical analysis. A P-value of $<0.05$ was considered to indicate a statistically significant difference. 

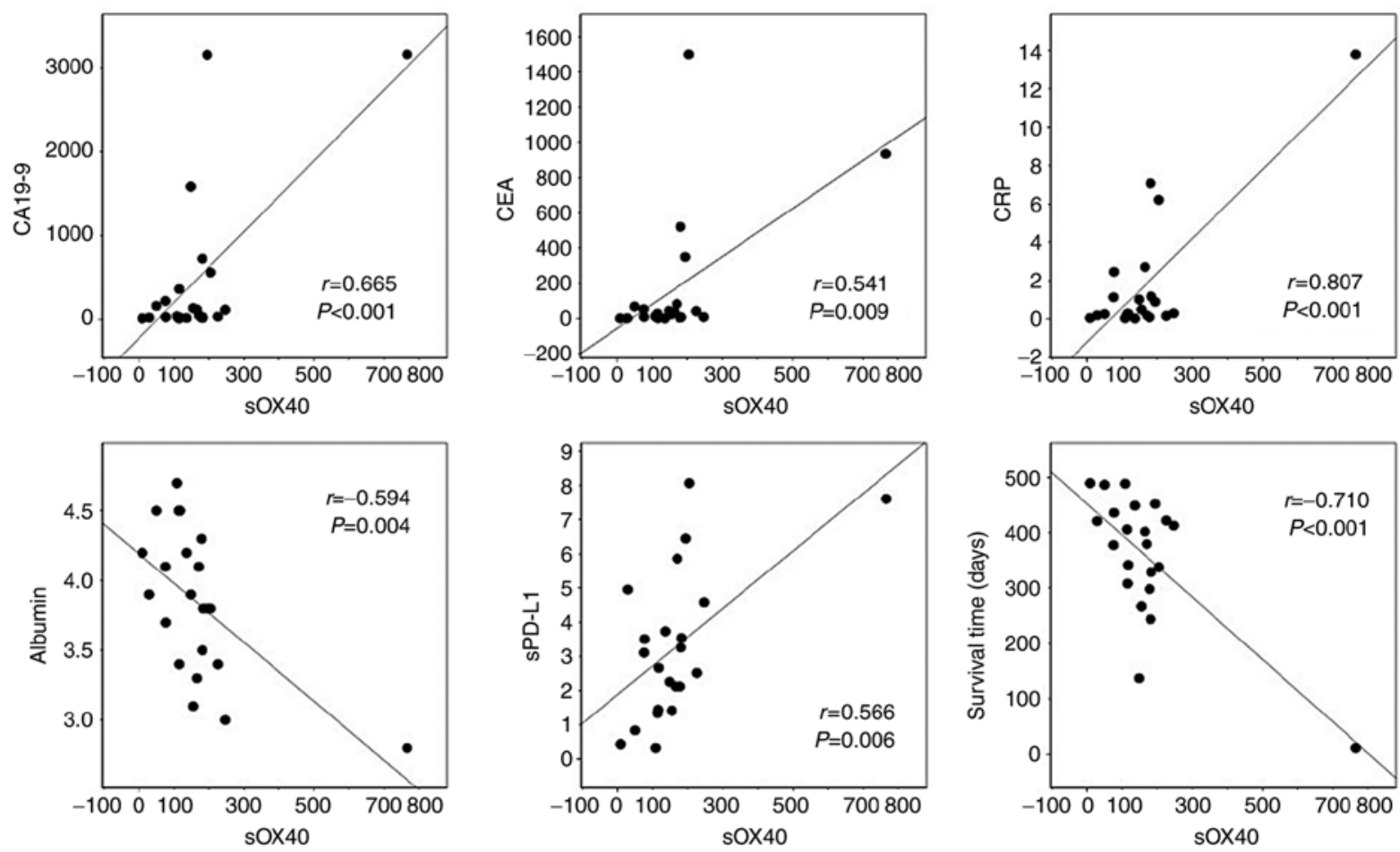

Figure 2. Correlation of blood OX40 levels with laboratory findings and survival time of the CRC patients. CRC, colorectal cancer. OX40, tumor necrosis factor receptor superfamily, member 4 .

\section{Results}

Blood sOX40 levels are positively correlated with the blood levels of tumor markers and CRP but negatively correlated with that of albumin. Table I reveals the characteristics of 22 patients with advanced CRC. Twelve males and 10 females were examined, and their median age was 71.5 years (29-81). Nine patients were firstly diagnosed, and the remaining 13 patients had postsurgical recurrence. Eighteen out of 22 patients had stage IV, 2 had stage III and 2 had stage II CRC. All patients received chemotherapy (adjuvant, 4; 1st line, 18) based on UFT or cisplatin.

The blood levels of sOX40 in CRC patients were significantly higher than those of healthy adults (Fig. 1). The median value of blood sOX40 level of the healthy adults was $71.0(n=10)$, and that of the CRC patients was $150.5(n=22)$.

The association between blood sOX40 levels and the clinical characteristics of the patients was investigated. Blood sOX40 levels were negatively associated with survival time in clinical characteristics (Table II and Fig. 2). In laboratory findings, blood sOX40 levels were positively correlated with blood levels of CA19-9, CEA, CRP and SPD-L1 but negatively correlated with blood albumin levels (Table II and Fig. 2).

Blood sOX40 levels are not associated with the expression of cytokines or PD-1 in PBMCs. Cellular OX40 is generally expressed on activated immune cells (14). Accordingly, the expression of mRNAs encoding cytokines that positively or negatively regulate T-cell immunity was examined for the association of blood sOX40 levels. Blood sOX40 levels were not associated with mRNA expression encoding IL-6, IL-10, IL-4 and IFN- $\gamma$ or the ratio of IL-10/IFN- $\gamma$ (Table III).

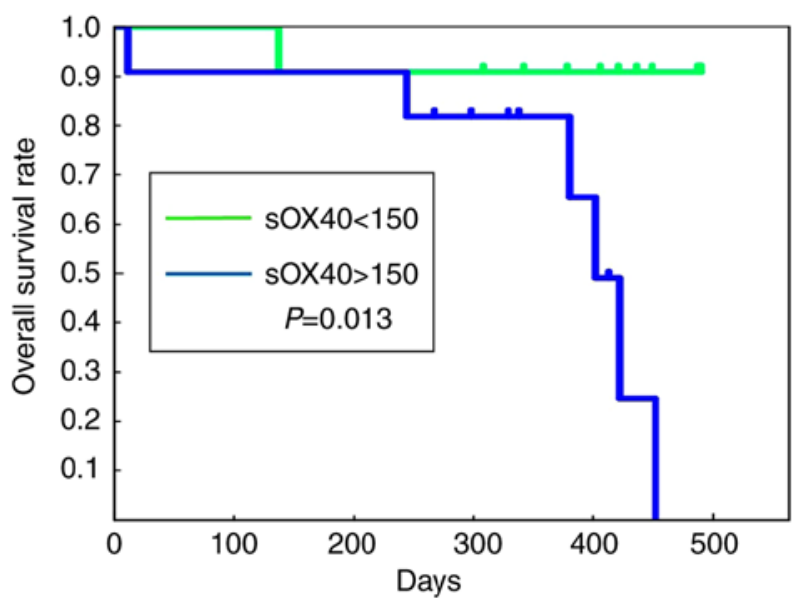

Figure 3. Kaplan-Meier curves of overall survival according to the blood level of OX40. Survival analysis was performed using the Kaplan-Meier estimate. P-values were calculated according to the log-rank test.

PD-1 expressed on T cells is a marker for T-cell activation or exhaustion (11). Blood sOX40 levels were not associated with the frequency of PD-1-expressing immune cells (Table III).

High blood sOX40 levels are significantly correlated with reduced survival in CRC patients. The prognostic value of the clinical factors of the CRC patients was examined. In both univariate and multivariate analyses, blood sOX40 levels were negatively correlated with the survival time of the patients, and high blood sOX40 levels were significantly correlated with a reduced survival of the patients (Table IV). No other factors were revealed to be prognostic factors. Fig. 3 shows 
Table IV. Prognostic value of blood sOX40 level for the overall survival by Cox proportional hazards model.

\begin{tabular}{|c|c|c|c|c|}
\hline Variables & No. & HR & $95 \% \mathrm{CI}$ & P-value \\
\hline \multicolumn{5}{|l|}{ Univariate analysis } \\
\hline \multicolumn{5}{|l|}{ Age, years } \\
\hline$\leq 70$ & 9 & 1.00 & & \\
\hline$>70$ & 13 & 1.72 & $0.32-9.11$ & 0.52 \\
\hline \multicolumn{5}{|l|}{ Sex (male vs. female) } \\
\hline Female & 9 & 1.00 & & \\
\hline Male & 13 & 0.59 & $0.13-2.80$ & 0.59 \\
\hline \multicolumn{5}{|l|}{ WBC (cells $/ \mu 1)$} \\
\hline$\leq 9,000$ & 17 & 1.00 & & \\
\hline$>9,000$ & 5 & 3.14 & $0.70-14.18$ & 0.14 \\
\hline \multicolumn{5}{|l|}{ LDH (U/l) } \\
\hline$\leq 400$ & 17 & 1.00 & & \\
\hline$>400$ & 5 & 1.67 & $0.32-8.66$ & 0.54 \\
\hline \multicolumn{5}{|l|}{ Albumin $(\mathrm{g} / \mathrm{dl})$} \\
\hline$\leq 3.8$ & 8 & 1.00 & & \\
\hline$>3.8$ & 14 & 0.25 & $0.05-1.39$ & 0.11 \\
\hline \multicolumn{5}{|l|}{ CRP (mg/dl) } \\
\hline$\leq 0.4$ & 12 & 1.00 & & \\
\hline$>0.4$ & 10 & 5.24 & $0.99-27.60$ & 0.051 \\
\hline \multicolumn{5}{|l|}{ CEA (ng/ml) } \\
\hline$\leq 50.0$ & 15 & 1.00 & & \\
\hline$>50.0$ & 7 & 3.21 & $0.70-14.77$ & 0.13 \\
\hline \multicolumn{5}{|l|}{ CA19-9 (U/ml) } \\
\hline$\leq 100$ & 11 & 1.00 & & \\
\hline$>100$ & 11 & 3.64 & $0.69-19.16$ & 0.13 \\
\hline \multicolumn{5}{|l|}{ Creatinine (mg/dl) } \\
\hline$\leq 1.0$ & 19 & 1.00 & & \\
\hline$>1.0$ & 3 & 0.83 & $0.10-6.95$ & 0.86 \\
\hline \multicolumn{5}{|l|}{ sOX40 } \\
\hline$\leq 150$ & 11 & 1.00 & & \\
\hline$>150$ & 11 & 9.80 & $1.15-83.41$ & 0.037 \\
\hline \multicolumn{5}{|l|}{ Multivariate analysis } \\
\hline Age ( $\leq 70$ vs. $>70)$ & - & 0.97 & $0.12-7.94$ & 0.98 \\
\hline Sex (male vs. female) & - & 0.93 & $0.11-8.28$ & 0.95 \\
\hline Creatinine $(\leq 1.0$ vs. $>1.0)$ & - & 0.92 & $0.08-10.29$ & 0.95 \\
\hline sOX40 ( $\leq 150$ vs. $>150)$ & - & 9.67 & $1.07-87.59$ & 0.044 \\
\hline
\end{tabular}

sOX40, soluble OX40; WBC, white blood cell, LDH, lactate dehydrogenase; CRP, C-reactive protein; CEA, carcinoembryonic antigen; CA19-9, carbohydrate antigen 19-9; OX40, tumor necrosis factor receptor superfamily, member 4.

Kaplan-Meier curves of overall survival of the patients based on the blood levels of sOX40. The patients with blood sOX40 levels $<150 \mathrm{pg} / \mathrm{ml}$ exhibited a longer survival time, while those with levels $>150 \mathrm{pg} / \mathrm{ml}$ exhibited a significantly shorter survival time.

OX40 mRNA expression of the PBMCs of patients is not associated with blood $\mathrm{SOX} 40$ levels. Jurkat cells activated by PMA treatment enhanced the expression of CD69, an activation marker of T cells, and OX40 (Figs. 4 and S1) as well as the release of sOX40 into the culture supernatants. PMA treatment also upregulated OX40 mRNA expression in Jurkat cells (Fig. 4). However, there was no correlation between OX40 mRNA expression in the PBMCs of the patients and the blood sOX40 levels $(\mathrm{P}=0.2474)$ (Fig. 5).

\section{Discussion}

The present study demonstrated that the prognosis of CRC patients with high blood levels of sOX40 was worse than those with low blood levels of sOX40. The survival time of the 

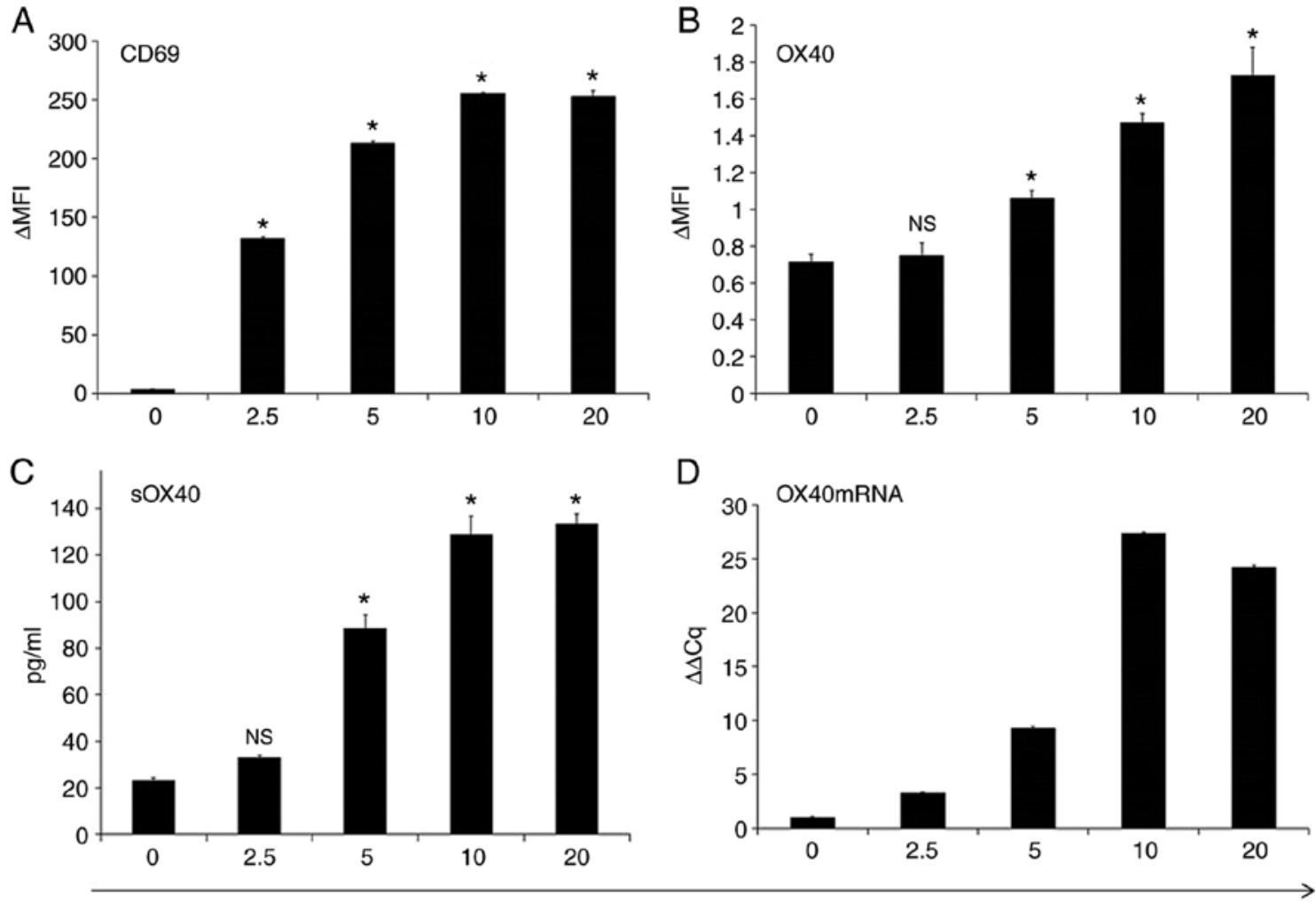

PMA (ng/ml)

Figure 4. PMA-activated Jurkat cells upregulate OX40 mRNA expression and sOX40 production. Jurkat cells were seeded in a $24-$ well plate $(10 \% / \mathrm{ml} / \mathrm{well})$ and treated with PMA $(0,2.5,5,10$ and $20 \mathrm{ng} / \mathrm{ml})$ for $4 \mathrm{~h}$. After washing cells with PBS, the cells were further incubated for $48 \mathrm{~h}$ in RPMI-1640 medium supplemented with 10\% FBS. The expression of (A) CD69 and (B) OX40 on the cell surface was analyzed by flow cytometry. The amount of (C) sOX40 in the culture supernatants was determined by ELISA. (D) OX40 mRNA expression was analyzed by qRT-PCR. OX40 mRNA is expressed as relative values to OX40 mRNA at PMA $0 \mathrm{ng} / \mathrm{ml}$, shown as 1 . "P<0.01 vs. untreated samples. Error bars represent the SD. PMA, phorbol 12-myristate 13-acetate; OX40, tumor necrosis factor receptor superfamily, member 4; sOX40, soluble OX40; n.s., not significant.

patients with high blood sOX40 levels was significantly shorter than those with low blood sOX40 levels. It is conceivable that sOX40 in the blood blocks the interaction between OX40 on $\mathrm{T}$ cells and OX40L on APCs, resulting in the suppression of $\mathrm{T}$ cell activation and $\mathrm{T}$ cell-mediated antitumor immunity. The artificially created OX40-immunoglobulin (OX40-Ig) fusion protein revealed activity resembling that of sOX40, preventing OX40 on T cells from reaching OX40L on APC, thus reducing the T-cell response. Experiments in mice have demonstrated that the administration of OX40-Ig reduces the T cellmediated immune response $(24,28)$ and that the administration of OX40L-Ig, conversely, enhances it, including antitumor immunity $(16,29)$. The fact that a dense infiltration of TILs is associated with a favorable prognosis of CRC indicates that intrinsic cellular immunity may elicit a suppressive activity regarding the development of CRC $(2,3,5,6)$. The suppression of T-cell activation by the blockade of the OX40/OX40L interaction by sOX40 may lead to the promotion of tumor development. In fact, in the present study, patients with higher blood levels of sOX40 exhibited higher blood levels of CEA, CA19-9 and CRP as well as lower blood levels of blood albumin. It has previously been reported that high blood levels of sPD-L1 indicate a reduced survival time in non-small cell lung cancer patients (30), indicating that SPD-L1 exhibits an immune-suppressive activity that promotes tumor development. In CRC patients, although SPD-L1 was not associated with the prognosis of the patients, the blood levels of sOX40

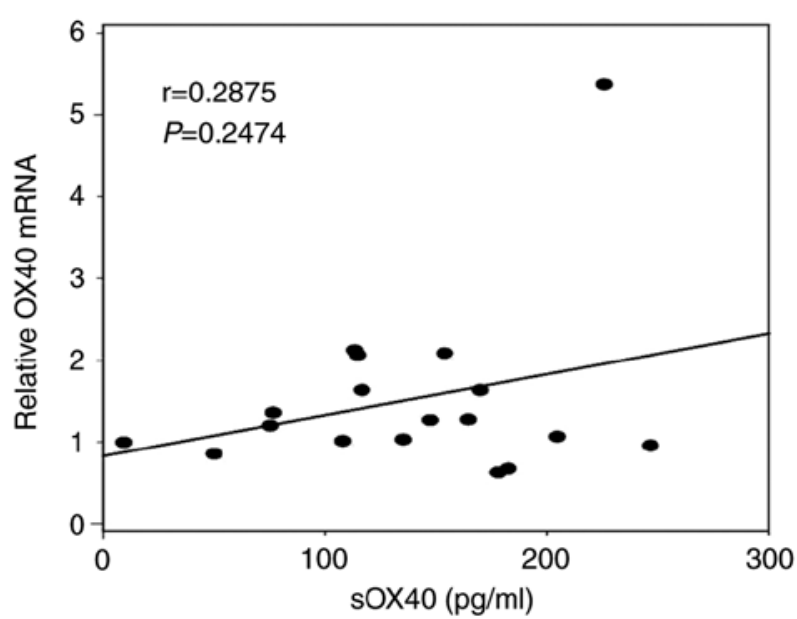

Figure 5. Correlation between blood sOX40 levels and OX40 mRNA expression in the PBMCs of CRC patients. sOX40, soluble OX40; OX40, tumor necrosis factor receptor superfamily, member 4; PBMCs, peripheral blood mononuclear cells; CRC, colorectal cancer.

were well correlated with those of sPD-L1. These results indicated that the soluble forms of immune checkpoint molecules may modulate the status of antitumor immunity and affect the prognosis of CRC patients.

The sOX40 concentration of $\sim 150-250 \mathrm{pg} / \mathrm{ml}$ in the blood of the CRC patients, however, appears to be too low to block 
the functional OX40-OX40L interaction. It is hypothesized that the levels of blood sOX40 would change according to the intensity of $\mathrm{T}$ cell-mediated antitumor immune activity. This theory is suggested by the result revealed in Fig. 3, indicating that the release of sOX40 from $\mathrm{T}$ cells was significantly elevated by the activation of $\mathrm{T}$ cells. It is possible that activated $\mathrm{T}$ cells would be suppressed by sOX40-induced blockade of OX40/OX40L, and then inactivated $\mathrm{T}$ cells would produce less sOX40. Thus, it is surmised that, in the CRC patients with the sOX40 concentration of $\sim 150-250 \mathrm{pg} / \mathrm{ml}$, the antitumor T-cell response may have already been suppressed under the condition of the blockade of OX40/OX40L by sOX40. Fig. 1 demonstrates that one CRC patient exhibited a high level of blood sOX40 with short survival. In this patient, antitumor $\mathrm{T}$ cells may be activated first, however, subsequently, T-cell activation may have been vigorously suppressed by the release of sOX40, resulting in short survival.

Jurkat cells activated with PMA upregulated the expression of OX40 mRNA and the release of sOX40 into the culture supernatants. However, the blood levels of sOX40 in CRC patients were not correlated with the expression of OX40 mRNA in the PBMCs of patients. Two possible reasons for this discrepancy could be considered: $T$ cell activity was suppressed by the blockade of the OX40/OX40L interaction by $\mathrm{sOX} 40$ released by activated $\mathrm{T}$ cells, which is one of the autoregulatory feedback mechanisms that regulates overactivated $\mathrm{T}$ cell immunity. The other is that immune cells other than PBMCs actively release sOX40, of which activated $\mathrm{T}$ cells in the tumor microenvironment are the most suspected. $\mathrm{T}$ cells responding to the mutated tumor antigens in the tumor microenvironment are activated and express various immune checkpoint molecules that positively or negatively regulate T-cell activity (1). It has been reported that $\mathrm{OX} 40^{+} \mathrm{T}$ cells are infiltrated into the tumor tissues of CRC with favorable prognosis (31). It is possible that activation status of $\mathrm{T}$ cells eliciting significant surface OX40 expression but less production of sOX40 is ideal for efficient $\mathrm{T}$ cell-mediated antitumor immunity. However, further investigation is required concerning this point.

Several preclinical studies demonstrated that the stimulation of OX40 using an agonistic anti-OX40 antibody or the $\mathrm{OX} 40 \mathrm{~L} / \mathrm{Ig}$ fusion protein revealed promising antitumor activity (29,32-34). In addition to these therapies targeting OX40, new therapeutic modalities could be established by the regulation of sOX40 in blood. The depletion or absorption of sOX40 in blood could prevent the immune-suppressive blockade of the OX40/OX40L interaction and maintain $\mathrm{T}$ cells activated. The effect of immune checkpoint blockade therapy on CRC is limited, and only CRCs with high microsatellite instability are sensitive to the anti-PD1 antibody therapy (35). The regulation of sOX40 in the blood of CRC patients may shed light on new immunotherapies against CRC.

\section{Acknowledgements}

The authors would like to thank the American Journal Experts for significant language editing. The authors would like to thank Immuno-Biological Laboratories, Ltd. for providing the ELISA kit of sOX40.

\section{Funding}

No funding was received.

\section{Availability of data and materials}

The datasets used and/or analyzed during the current study are available from the corresponding author on reasonable request.

\section{Authors' contributions}

RS, YN, TN, MN and KA made substantial contributions to the acquisition, analysis and interpretation of data. YA made substantial contributions to the statistical analysis. SA was involved in drafting the manuscript and revising it critically for important intellectual content. YS made substantial contributions to the assay experiment for sOX40. MS made substantial contributions to the conception and design of the work and provided final approval of the version to be published. SH made substantial contributions to conception and design and provided final approval of the version to be published. All authors read and approved the manuscript and agree to be accountable for all aspects of the research in ensuring that the accuracy or integrity of any part of the work are appropriately investigated and resolved.

\section{Ethics approval and consent to participate}

The study protocol was approved by the Ethics Committee of The Jikei University School of Medicine (30-397 9418) and conducted in accordance with the Declaration of Helsinki. The informed consent for participation in the study was obtained from all participants. The patient, or parent, guardian or next of kin (in case of deceased patients) provided written informed consent for the publication of any associated data and accompanying images. The consent form is made available to the Editor if requested, and will be treated confidentially.

\section{Patient consent for publication}

Not applicable.

\section{Competing interests}

The authors declare that they have no competing interests.

\section{References}

1. Anari F, Ramamurthy $\mathrm{C}$ and Zibelman $\mathrm{M}$ : Impact of tumor microenvironment composition on therapeutic responses and clinical outcomes in cancer. Future Oncol 14: 1409-1421, 2018.

2. Huh JW, Lee JH and Kim HR: Prognostic significance of tumor-infiltrating lymphocytes for patients with colorectal cancer. Arch Surg 147: 366-372, 2012.

3. Galon J, Costes A, Sanchez-Cabo F, Kirilovsky A, Mlecnik B, Lagorce-Pagès $\mathrm{C}$, Tosolini $\mathrm{M}$, Camus $\mathrm{M}$, Berger $\mathrm{A}$, Wind $\mathrm{P}$, et al: Type, density, and location of immune cells within human colorectal tumors predict clinical outcome. Science 313: 1960-1964, 2006.

4. Teng F, Mu D, Meng X, Kong L, Zhu H, Liu S, Zhang J and Yu J: Tumor infiltrating lymphocytes (TILs) before and after neoadjuvant chemoradiotherapy and its clinical utility for rectal cancer. Am J Cancer Res 5: 2064-2074, 2015. 
5. Lee WS, Kang M, Baek JH, Lee JI and Ha SY: Clinical impact of tumor-infiltrating lymphocytes for survival in curatively resected stage IV colon cancer with isolated liver or lung metastasis. Ann Surg Oncol 20: 697-702, 2013

6. Kwak Y, Koh J, Kim DW, Kang SB, Kim WH and Lee HS: Immunoscore encompassing $\mathrm{CD}^{+}$and $\mathrm{CD} 8^{+} \mathrm{T}$ cell densities in distant metastasis is a robust prognostic marker for advanced colorectal cancer. Oncotarget 7: 81778-81790, 2016.

7. Yasuda K, Nirei T, Sunami E, Nagawa H and Kitayama J: Density of CD4(+) and CD8(+) T lymphocytes in biopsy samples can be a predictor of pathological response to chemoradiotherapy (CRT) for rectal cancer. Radiat Oncol 6: 49, 2011.

8. Halama N, Michel S, Kloor M, Zoernig I, Benner A, Spille A, Pommerencke T, von Knebel DM, Folprecht G, Luber B, et al: Localization and density of immune cells in the invasive margin of human colorectal cancer liver metastases are prognostic for response to chemotherapy. Cancer Res 71: 5670-5677, 2011.

9. Tanis E, Julié C, Emile JF, Mauer M, Nordlinger B, Aust D, Roth A, Lutz MP, Gruenberger T, Wrba F, et al: Prognostic impact of immune response in resectable colorectal liver metastases treated by surgery alone or surgery with perioperative FOLFOX in the randomised EORTC study 40983. Eur J Cancer 51: 2708-2717, 2015

10. Foell J, Hewes B and Mittler RS: T cell costimulatory and inhibitory receptors as therapeutic targets for inducing anti-tumor immunity. Curr Cancer Drug Targets 7: 55-70, 2007.

11. Li J and Gu J: Efficacy and safety of PD-1 inhibitors for treating advanced melanoma: A systematic review and meta-analysis. Immunotherapy 10: 1293-1302, 2018

12. Valecha GK, Vennepureddy A, Ibrahim U, Safa F, Samra B and Atallah JP: Anti-PD-1/PD-L1 antibodies in non-small cell lung cancer: The era of immunotherapy. Expert Rev Anticancer Ther 17: 47-59, 2017

13. Ishii N, Takahashi T, Soroosh P and Sugamura K: OX40-OX40 ligand interaction in T-cell-mediated immunity and immunopathology. Adv Immunol 105: 63-98, 2010.

14. Croft M, So T, Duan W and Soroosh P: The significance of OX40 and OX40L to T-cell biology and immune disease. Immunol Rev 229: 173-191, 2009.

15. Gramaglia I, Weinberg AD, Lemon $M$ and Croft M: Ox-40 ligand: A potent costimulatory molecule for sustaining primary CD4 T cell responses. J Immunol 161: 6510-6517, 1998.

16. Gramaglia I, Jember A, Pippig SD, Weinberg AD, Killeen N and Croft M: The OX40 costimulatory receptor determines the development of CD4 memory by regulating primary clonal expansion. J Immunol 165: 3043-3050, 2000.

17. Bansal-Pakala P, Halteman BS, Cheng $\mathrm{MH}$ and Croft $\mathrm{M}$ : Costimulation of CD8 T cell responses by OX40. J Immunol 172: 4821-4825, 2004.

18. Vu MD, Xiao X, Gao W, Degauque N, Chen M, Kroemer A, Killeen N, Ishii N and Li XC: OX40 costimulation turns off Foxp $^{+}$Tregs. Blood 110: 2501-2510, 2007.

19. So T and Croft M: Cutting edge: OX40 inhibits TGF-beta- and antigen-driven conversion of naive $\mathrm{CD} 4 \mathrm{~T}$ cells into $\mathrm{CD} 25^{+} \mathrm{Foxp} 3^{+}$ T cells. J Immunol 179: 1427-1430, 2007.

20. Weinberg AD, Rivera MM, Prell R, Morris A, Ramstad T, Vetto JT, Urba WJ, Alvord G, Bunce C and Shields J: Engagement of the OX-40 receptor in vivo enhances antitumor immunity. J Immunol 164: 2160-2169, 2000.

21. Piconese S, Valzasina B and Colombo MP: OX40 triggering blocks suppression by regulatory $\mathrm{T}$ cells and facilitates tumor rejection. J Exp Med 205: 825-839, 2008.
22. Pan PY, Zang Y, Weber K, Meseck ML and Chen SH: OX40 ligation enhances primary and memory cytotoxic $\mathrm{T}$ lymphocyte responses in an immunotherapy for hepatic colon metastases. Mol Ther 6: 528-536, 2002.

23. Tanaka Y, Takahashi Y, Tanaka R, Miyagi T, Saito M and Fukushima T: Association of high levels of plasma OX40 with acute adult T-cell leukemia. Int J Hematol 109: 319-327, 2019

24. Weinberg AD, Wegmann KW, Funatake $\mathrm{C}$ and Whitham RH: Blocking OX-40/OX-40 ligand interaction in vitro and in vivo leads to decreased $\mathrm{T}$ cell function and amelioration of experimental allergic encephalomyelitis. J Immunol 162: 1818-1826, 1999.

25. Weiss A, Wiskocil RL, and Stobo JD: The role of T3 surface molecules in the activation of human T cells: A two-stimulus requirement for IL 2 production reflects events occurring at a pre-translational level. J Immunol 133: 123-128, 1984.

26. Hayashi K, Nagasaki E, Kan S, Ito M, Kamata Y, Homma S and Aiba K: Gemcitabine enhances rituximab-mediated complement-dependent cytotoxicity to B cell lymphoma by CD20 upregulation. Cancer Sci 107: 682-689, 2016

27. Livak KJ and Schmittgen TD: Analysis of relative gene expression data using real-time quantitative PCR and the 2(-Delta Delta C(T)) method. Methods 25: 402-408, 2001.

28. Higgins LM, McDonald SA, Whittle N, Crockett N, Shields JG and MacDonald TT: Regulation of T cell activation in vitro and in vivo by targeting the OX40-OX40 ligand interaction: Amelioration of ongoing inflammatory bowel disease with an OX40-IgG fusion protein, but not with an OX40 ligand-IgG fusion protein. J Immunol 162: 486-493, 1999.

29. Sadun RE, Hsu WE, Zhang N, Nien YC, Bergfeld SA, Sabzevari H, Lutsiak ME, Khawli L, Hu P and Epstein AL: $\mathrm{Fc}-\mathrm{mOX} 40 \mathrm{~L}$ fusion protein produces complete remission and enhanced survival in 2 murine tumor models. J Immunother 31: 235-245, 2008

30. Okuma Y, Hosomi Y, Nakahara Y, Watanabe K, Sagawa Y and Homma S: High plasma levels of soluble programmed cell death ligand 1 are prognostic for reduced survival in advanced lung cancer. Lung Cancer 104: 1-6, 2017.

31. Weixler B, Cremonesi E, Sorge R, Muraro MG, Delko T, Nebiker CA, Däster S, Governa V, Amicarella F, Soysal SD et al: OX40 expression enhances the prognostic significance of CD8 positive lymphocyte infiltration in colorectal cancer. Oncotarget 6: 37588-37599, 2015.

32. Sagiv-Barfi I, Czerwinski DK, Levy S, Alam IS, Mayer AT, Gambhir SS and Levy R: Eradication of spontaneous malignancy by local immunotherapy. Sci Transl Med 10: pii: eaan4488, 2018.

33. Metzger TC, Long H, Potluri S, Pertel T, Bailey-Bucktrout SL, Lin JC, Fu T, Sharma P, Allison JP and Feldman RM: ICOS promotes the function of $\mathrm{CD}^{+}{ }^{+}$effector $\mathrm{T}$ cells during Anti-OX40-mediated tumor rejection. Cancer Res 76: 3684-3689, 2016.

34. Gough MJ, Ruby CE, Redmond WL, Dhungel B, Brown A and Weinberg AD: OX40 agonist therapy enhances CD8 infiltration and decreases immune suppression in the tumor. Cancer Res 68: 5206-5215, 2008.

35. Mehrvarz Sarshekeh A, Overman MJ and Kopetz S: Nivolumab in the treatment of microsatellite instability high metastatic colorectal cancer. Future Oncol 14: 1869-1874, 2018 